\title{
43
}

\section{Halloween (Gitterrätsel)}

Die Toten kommen aus ihren Gräbern, Monster füllen die Straßen - und die Kinder freuen sich über Eimerladungen Süßes. Trage die gesuchten Begriffe in das Gitter ein. Die Buchstaben in den grauen Feldern

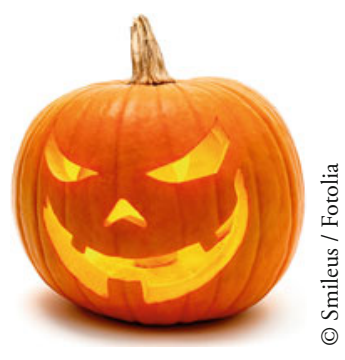
ergeben - von oben nach unten gelesen - das Lösungswort.

(1) der Teil im vegetativen Nervensystem, der die Handlungsbereitschaft erhöht

(2) der „Mandelkern“ im Kopf

(3) ein „Würmer-Salat“ zu Halloween imitiert Individuen dieser Tierfamilie (lat.)

(4) die Dame auf dem Besen

(5) versuchte Angstminderung durch Pharmaka („Angstauflösung“)

(6) spürbare, starke Aktivität unserer Blutpumpe (ugs.)

(7) wird im Körper bei Stress ausgeschüttet

(8) unersetzlich als nervliche Schaltzentrale; ein Hingucker als Halloween-Deko

(9) steigt im Körper bei Stress an (dt.)

(10) „vernetzte“ tierische Auslöserin einer häufigen Phobie (dt.)

(11) das Symbol für Halloween schlechthin ( $\ddot{\mathrm{u}}=\mathrm{ue})$

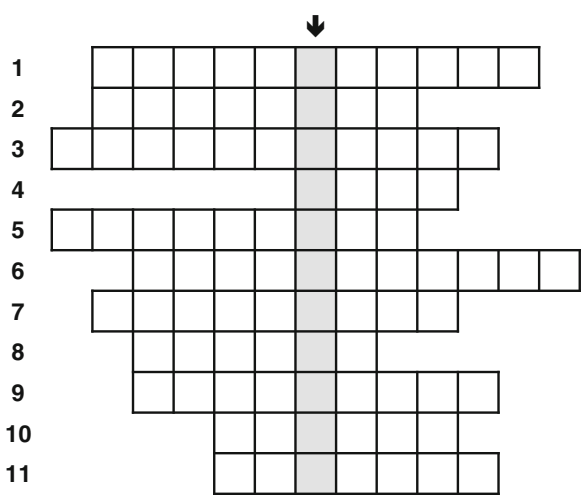

Lösung:

(C) Springer-Verlag Berlin Heidelberg 2016

C. Reinbold, Fetthenne, Moderlieschen, Warzenbeißer,

DOI 10.1007/978-3-662-52817-4_43 